\title{
Calculations Predict a Large Inverse H/D Kinetic Isotope Effect on the Rate of Tunneling in the Ring Opening of Cyclopropylcarbinyl Radical
}

\author{
Xue Zhang, Ayan Datta, David A. Hrovat, and Weston Thatcher Borden* \\ Department of Chemistry and Center for Advanced Scientific Computing and Modeling, University of North Texas, \\ 1155 Union Circle \#305070, Denton, Texas 76203-5017
}

Received September 1, 2009; E-mail: borden@unt.edu

Tunneling rates are expected to decrease exponentially with the square root of the effective tunneling mass. ${ }^{1 \mathrm{a}}$ Therefore, on substitution of a heavier for a lighter isotope, the observation of a large kinetic isotope effect (KIE), involving a substantial decrease in rate constant, is a commonly used diagnostic for a large contribution from quantum mechanical tunneling to a reaction. ${ }^{1}$

However, in this communication we report the results of calculations that make the opposite prediction about some of the KIEs on the ring opening of cyclopropylcarbinyl radical (1) to 3-butene-1-yl radical $(2)^{2}$ by tunneling at cryogenic temperatures. ${ }^{3}$ Substitution of a heavier for a lighter isotope at the radical center $\left(\mathrm{C}^{1}\right)$ of $\mathbf{1}$ is calculated to accelerate the rate of tunneling, giving KIEs at this carbon that are inverse. Of particular note is our prediction that substitution of deuterium for both hydrogens at $\mathrm{C}^{1}$ will lead to a nearly 3 -fold increase in the rate of reaction at temperatures so low that ring opening proceeds exclusively by tunneling from the lowest vibrational level.

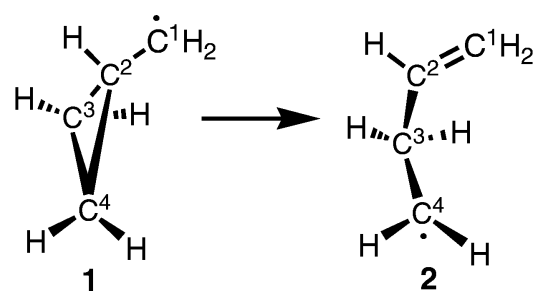

As in our previous computational study of tunneling in the ring opening of $\mathbf{1}$ to $2,{ }^{3}$ we performed unrestricted electronic structure calculations with $\mathrm{B}^{2} \mathrm{LYP}^{4}$ and the $6-31 \mathrm{G}(\mathrm{d})$ basis set, ${ }^{5}$ to carry out direct dynamics calculations of the rate of this reaction. Canonical variational transition state theory $(\mathrm{CVT})^{6}$ was used to locate the transition structure (TS) for the ring opening of $\mathbf{1}$ to 2 . Quantum effects on the reaction dynamics were computed semiclassically, using the small-curvature tunneling (SCT) approximation. $^{7}$ The direct dynamics calculations were carried out with GAUSSRATE $^{8}$ as the interface between Gaussian $03^{9}$ and POLYRATE. ${ }^{10}$

The results of our calculations are summarized in Table 1, which gives the KIEs on the breaking of the bond between $\mathrm{C}^{2}$ and $\mathrm{C}^{4}$ in 1. The KIEs in Table 1 were calculated at $20 \mathrm{~K}$. However, calculations at lower temperatures give exactly the same results, because below $20 \mathrm{~K}$ all of the reaction occurs by tunneling from the lowest vibrational level of $\mathbf{1}$.

Not surprisingly, the largest KIEs on the ring opening of $\mathbf{1}$ are calculated for substitution of ${ }^{13} \mathrm{C}$ or ${ }^{14} \mathrm{C}$ for ${ }^{12} \mathrm{C}$ or of $\mathrm{D}_{2}$ for $\mathrm{H}_{2}$ at $\mathrm{C}^{4}$. An animation of the transition vector, the vibration which has an imaginary frequency in the TS, shows that, in the cleavage of the bond between $\mathrm{C}^{2}$ and $\mathrm{C}^{4}$, the latter carbon moves the most. ${ }^{11}$ Since motion of $\mathrm{C}^{4}$ is the largest contributor to the internal displacements that are necessary for passage of $\mathbf{1}$ over, or tunneling of $\mathbf{1}$ through, the barrier that separates it from 2, isotopic substitution at $\mathrm{C}^{4}$ would be expected to have the largest effect on increasing the effective tunneling mass and, hence, on retarding the rate of tunneling.

Table 1. SCT KIEs Calculated for Ring Opening of $\mathbf{1}$ to 2 at $20 \mathrm{~K}$

\begin{tabular}{lccc}
\hline Carbon & $k\left({ }^{12} \mathrm{C} /{ }^{13} \mathrm{C}\right)$ & $k\left({ }^{12} \mathrm{C} /{ }^{14} \mathrm{C}\right)$ & $k\left(\mathrm{CH}_{2} / \mathrm{CD}_{2}\right)$ \\
\hline $\mathrm{C}^{1}$ & 0.96 & 0.93 & 0.37 \\
$\mathrm{C}^{2}$ & 1.77 & 2.99 & $1.49^{a}$ \\
$\mathrm{C}^{3}$ & 1.12 & 1.24 & 0.85 \\
$\mathrm{C}^{4}$ & 2.42 & 5.46 & 6.47 \\
$\mathrm{C}^{3} / \mathrm{C}^{4}$ & $2.17^{b}$ & $4.41^{c}$ & $7.57^{d}$
\end{tabular}

${ }^{a} \mathrm{CH} / \mathrm{CD} .{ }^{b}$ Predicted ratio in 2 of ${ }^{13} \mathrm{C}$ at $\mathrm{C}^{3}$ to ${ }^{13} \mathrm{C}$ at $\mathrm{C}^{4}$. ${ }^{c}$ Predicted ratio in $\mathbf{2}$ of ${ }^{14} \mathrm{C}$ at $\mathrm{C}^{3}$ to ${ }^{14} \mathrm{C}$ at $\mathrm{C}^{4}$. ${ }^{d}$ Predicted ratio in $\mathbf{2}$ of $\mathrm{D}_{2}$ at $\mathrm{C}^{3}$ to $\mathrm{D}_{2}$ at $\mathrm{C}^{4}$.

Certainly the most surprising result in Table 1 is the large, inverse KIE, predicted for substitution of $\mathrm{D}_{2}$ for $\mathrm{H}_{2}$ at $\mathrm{C}^{1}$. Instead of slowing the rate of tunneling from 1 to 2 , substitution of $\mathrm{CD}_{2}$ for $\mathrm{CH}_{2}$ at $\mathrm{C}^{1}$ is actually computed to accelerate the rate of ring opening by a factor of $1 / 0.37=2.7$. This result shows that H/D KIEs on tunneling rates need not necessarily be large and normal but can, in fact, be large and inverse.

The explanation of the large, inverse KIE, predicted for substitution of $\mathrm{D}_{2}$ for $\mathrm{H}_{2}$ at $\mathrm{C}^{1}$ begins with the transition vector for ring opening of $\mathbf{1}$ to $\mathbf{2}$. The animation of this vibrational mode shows little or no motion at $\mathrm{C}^{1}{ }^{11}$ Therefore, one might have expected $k\left(\mathrm{CH}_{2} / \mathrm{CD}_{2}\right) \approx 1.00$ at this carbon. In fact, $k\left({ }^{12} \mathrm{C} /{ }^{14} \mathrm{C}\right)=0.93$ at $\mathrm{C}^{1}$. Since ${ }^{14} \mathrm{CH}_{2}$ and ${ }^{12} \mathrm{CD}_{2}$ have the same mass, the very different KIEs, computed for substitution of ${ }^{12} \mathrm{CD}_{2}$ and ${ }^{14} \mathrm{CH}_{2}$ at $\mathrm{C}^{1}$ of $\mathbf{1}$, indicate that motion of the hydrogens at $\mathrm{C}^{1}$ plays a prominent role in the large, inverse KIE that is computed for substitution of $\mathrm{D}_{2}$ for $\mathrm{H}_{2}$ at this carbon.

On ring opening of $\mathbf{1}$ to $\mathbf{2}$, a double bond between $\mathrm{C}^{1}$ and $\mathrm{C}^{2}$ in 2 replaces the single bond between these two carbons in $\mathbf{1}$. As a consequence of this change in bonding, the force constants for torsion about the $\mathrm{C}^{1}-\mathrm{C}^{2}$ bond and pyramidalization of $\mathrm{C}^{1}$ increase in both $\mathbf{2}$ and in the TS leading to it. Therefore, there are corresponding increases in the frequencies for these two vibrations. For $\mathrm{C}^{1} \mathrm{H}_{2}$ the torsional frequency is calculated to increase from 139.4 $\mathrm{cm}^{-1}$ in $\mathbf{1}$ to $498.1 \mathrm{~cm}^{-1}$ in the TS for ring opening of $\mathbf{1}$ to $\mathbf{2}$, and the pyramidalization frequency is calculated to increase from 461.5 $\mathrm{cm}^{-1}$ in $\mathbf{1}$ to $702.0 \mathrm{~cm}^{-1}$ in the TS. These increases in unscaled vibrational frequencies total $358.7+240.5=599.2 \mathrm{~cm}^{-1}$ and correspond to a net increase in the zero-point energies (ZPEs) of these two modes of $299.6 \mathrm{~cm}^{-1}=0.86 \mathrm{kcal} / \mathrm{mol}$ on going from 1 to the TS for ring opening of $\mathbf{1}$ to $2 .^{12}$

The 2-fold larger mass of deuterium, compared to protium, makes these increases in the unscaled, harmonic frequencies in the TS for ring opening of $\mathbf{1}$ to $\mathbf{2}$ smaller for $\mathrm{C}^{1} \mathrm{D}_{2}$ than for $\mathrm{C}^{1} \mathrm{H}_{2}$. The 
calculated increases are $380.1-101.8 \mathrm{~cm}^{-1}=278.3 \mathrm{~cm}^{-1}$ for $\mathrm{C}^{1} \mathrm{D}_{2}$ torsion and $561.4-414.1 \mathrm{~cm}^{-1}=147.3 \mathrm{~cm}^{-1}$ for $\mathrm{C}^{1} \mathrm{D}_{2}$ pyramidalization. Consequently, the net increase in the ZPEs for these two vibrations on going from $\mathbf{1}$ to the TS for ring opening to $\mathbf{2}$ is 212.8 $\mathrm{cm}^{-1}=0.61 \mathrm{kcal} / \mathrm{mol}$ for $\mathrm{C}^{1} \mathrm{D}_{2}$. Thus, the sum of the increases in these two ZPEs is smaller by $0.25 \mathrm{kcal} / \mathrm{mol}$ for $\mathrm{C}^{1} \mathrm{D}_{2}$ than for $\mathrm{C}^{1} \mathrm{H}_{2}$.

The calculated increases in the unscaled harmonic frequencies in going from $\mathbf{1}$ to the TS for its ring opening to $\mathbf{2}$ occur in vibrational coordinates that are orthogonal to the reaction coordinate. Therefore, the effect of the change in either frequency on the difference between the ZPEs in $\mathbf{1}$ and the TS for ring opening can be depicted schematically as in Figure 1.

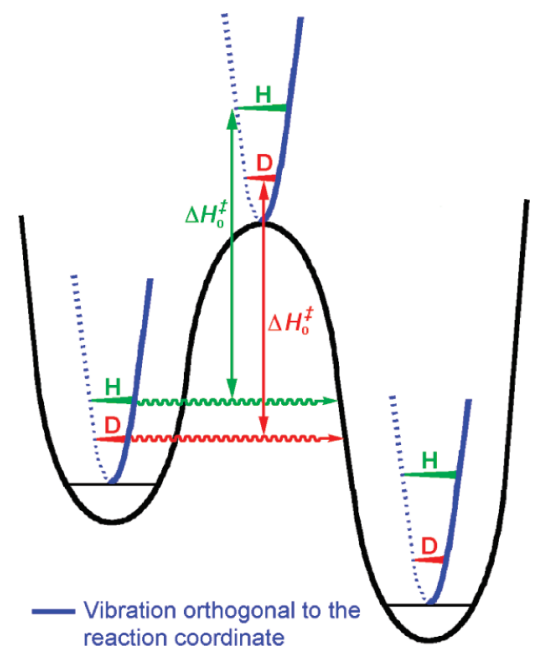

Figure 1. Schematic depiction of the effect on $\Delta H_{0}^{\ddagger}$, the effective height of the barrier through which tunneling must occur, of a vibration, orthogonal to the reaction coordinate, which increases in frequency in going from the reactant to the TS. If the increase in the ZPE that is associated with this vibration is greater for $\mathrm{H}$ than for $\mathrm{D}$, and if motion of $\mathrm{H}$ and $\mathrm{D}$ along the reaction coordinate is negligible, an inverse H/D KIE on tunneling can occur, since $\Delta H_{0}^{\ddagger}(\mathrm{H})$ is greater than $\Delta H_{0}^{\ddagger}(\mathrm{D})$.

For passage over the reaction barrier, the difference between $\Delta H_{0} \ddagger(\mathrm{H})$ and $\Delta H_{0} \ddagger(\mathrm{D})$ gives rise to a temperature-dependent, secondary, H/D KIE. In the rearrangement of $\mathbf{1}$ to $\mathbf{2}$ the difference between the calculated, zero-point-inclusive barrier heights for $\mathrm{H}_{2}$ and for $\mathrm{D}_{2}$ at $\mathrm{C}^{1}$ is $0.24 \mathrm{kcal} / \mathrm{mol}$, which is almost the same as the $0.25 \mathrm{kcal} / \mathrm{mol}$ sum of the differences between the changes in ZPEs for torsion about the bond between $\mathrm{C}^{1}$ and $\mathrm{C}^{2}$ and for pyramidalization at $\mathrm{C}^{1}$. At $20 \mathrm{~K}$ the effect of the $0.24 \mathrm{kcal} / \mathrm{mol}$ difference between the effective barrier heights for $\mathrm{H}$ and $\mathrm{D}$ gives rise to a very large, inverse, CVT KIE at $\mathrm{C}^{1}$ of $k(\mathrm{H}) / k(\mathrm{D})=0.0023$ for passage over the barrier. ${ }^{13}$ As shown in Table 1, the same difference in effective barrier heights is calculated to give rise to a smaller, inverse $\mathrm{KIE}$ at $\mathrm{C}^{1}$ of $k(\mathrm{H}) / k(\mathrm{D})=0.37$ on the rate of tunneling.

Isotopic substitution at $\mathrm{C}^{2}, \mathrm{C}^{3}$, and $\mathrm{C}^{4}$ affects the KIEs for tunneling in two ways. The substitution of a heavier for a lighter isotope not only increases the effective tunneling mass but also, as shown schematically in Figure 1, alters the effective barrier height through which tunneling occurs. For example, rehybridization of $\mathrm{C}^{3}$ on ring opening results in a $0.06 \mathrm{kcal} / \mathrm{mol}$ decrease in the effective barrier height upon substitution of $\mathrm{D}_{2}$ for $\mathrm{H}_{2}$ at this carbon. This decrease, coupled with the small amount of motion of $\mathrm{C}^{3}$ in the transition vector, ${ }^{11}$ causes the H/D KIE for substitution of $\mathrm{D}_{2}$ for $\mathrm{H}_{2}$ at $\mathrm{C}^{3}$ to be inverse, rather than normal, unlike the isobaric substitution of ${ }^{14} \mathrm{C}$ for ${ }^{12} \mathrm{C}$ at this carbon.

Obtaining experimental ratios of rate constants that would be precise enough to compare with the predicted KIEs in Table 1 might be difficult, due to the differences between the rates at which molecules at different types of sites react in matrix isolation. ${ }^{14}$ However, the ratios of the KIEs at $\mathrm{C}^{3}$ and $\mathrm{C}^{4}$ in Table 1 predict whether it is the isotopically substituted or unsubstituted $\mathrm{C}-\mathrm{C}$ bond in $\mathbf{1}$ that preferentially cleaves. After chemical trapping of $\mathbf{2}$, accurate measurements of the ratio of isotopes at these two carbons could be made. Assay of the distribution of ${ }^{13} \mathrm{C}$ at $\mathrm{C}^{3}$ and $\mathrm{C}^{4}$ in the product by natural-abundance ${ }^{13} \mathrm{C}$ NMR should be particularly easy. Such experiments are underway, and the results will be reported in due course. ${ }^{15}$

Supporting Information Available: The optimized UB3LYP/6$31 \mathrm{G}(\mathrm{d})$ geometries and energies for 1, 2, and the transition structure connecting them; the CVT and SCT rate constants for ring opening of 1 to 2 ; and complete lists of authors for refs 9 and 10. This material is available free of charge via the Internet at http://pubs.acs.org.

Acknowledgment. We thank the National Science Foundation and the Robert A. Welch Foundation for support of this research. Some of the results reported here were obtained on computers, purchased with funds provided by the National Science Foundation under Grant CHE-0741936.

\section{References}

(1) Reviews:(a) Bell, R. P. The Tunneling Effect in Chemistry; Chapman and Hall: London and New York, 1980. (b) Isotope Effects in Chemistry and Biology; Kohen, A. Limbach, H.-H., Eds.; Taylor and Francis: Boca Raton, FL, 2006. (c) Hynes, J. T., Klinman, J. P., Limbach, H.-H., Schowen, R. L. Hydrogen Transfer Reactions, Vols. 1-4; Wiley-VCH: Weinhein, 2007. (d) Sheridan, R. S. In Reviews in Reactive Intermediate Chemistry; Moss, R. A., Platz, M. S., Jones, M. J., Jr., Eds.; John Wiley \& Sons: New York, 2007; pp 415-64.

(2) (a) Newcomb, M.; Glenn, A. G. J. Am. Chem. Soc. 1989, 111, 275. (b) Maillard, B.; Forrest, D.; Ingold, K. U. J. Am. Chem. Soc. 1976, 98, 7024. (c) Beckwith, A. L. J.; Bowry, V. W.; Moad, G. J. Org. Chem. 1988, 53, 1632.

(3) Datta, A.; Hrovat, D. A.; Borden, W. T. J. Am. Chem. Soc. 2008, 130, 6684.

(4) (a) Becke, A. D. J. Chem. Phys. 1993, 98, 5648. (b) Lee, C.; Yang, W.; Parr, R. G. Phys Rev. B 1988, 37, 78. (c) Miehlich, B.; Savin, A.; Stoll, H.; Preuss, H. Chem. Phys. Lett. 1989, 157, 200.

(5) Hariharan, P. C.; Pople, J. A. Theor. Chim. Acta 1973, 28, 213.

(6) Truhlar, D. G.; Garrett, B. C. Annu. Rev. Phys. Chem. 1984, 35, 159.

(7) Fernandez-Ramos, A.; Ellingson, B. A.; Garrett, B. C.; Truhlar, D. G. In Reviews in Computational Chemistry, 23; Lipkowitz, K. B., Cundari, T. R., Eds.; Wiley-VCH: Hoboken, NJ, 2007; pp 125-232.

(8) Corchado, J. C.; Chuang, Y.-Y.; Coitino, E. L.; Truhlar, D. G. GAUSSRATEversion 9.5; University of Minnesota: Minneapolis, MN, 2007.

(9) Frisch, M. J.; Gaussian 03, revision D.02; Gaussian, Inc.: Wallingford, CT, 2004.

(10) Corchado, J. C.; POLYRATE, version 9.5; University of Minnesota: Minneapolis, MN, 2007.

(11) An animation of the transition vector for conversion of $\mathbf{1}$ to $\mathbf{2}$ is available at http://www.chem.unt.edu/faculty/Borden/cPrCarbinyl_TVec.gif.

(12) The change in ZPE of $1.69 \mathrm{kcal} / \mathrm{mol}$ between $\mathbf{1}$ and $\mathbf{2}$ for these modes is, as expected, larger.

(13) However, at $20 \mathrm{~K}$ the rate constant for passage of $\mathbf{1}$ over the barrier is calculated to be $k=2.54 \times 10^{-72} \mathrm{~s}^{-1}$, compared to $k=2.22 \times 10^{-2} \mathrm{~s}^{-1}$ for tunneling through the barrier. ${ }^{3}$ Therefore, at $20 \mathrm{~K}$, no molecules actually do react by passage over the barrier.

(14) See, for example: Sponsler, M. B.; Jain, R.; Coms, F. D.; Dougherty, D. A. J. Am. Chem. Soc. 1989, 111, 2240.

(15) James, O.; Hrovat, D. A., Borden, W. T., Singleton, D. A. To be submitted for publication.

JA907406Q 